\title{
EXPERIÊNCIA DE ASSESSORIA JUNTO ÀS COMUNIDADES ATINGIDAS PELO MINERODUTO DA FERROUS NA ZONA DA MATA MINEIRA
}

\author{
Marcelo Leles Oliveira \\ Universidade Federal de Viçosa \\ mlromarco@yahoo.com.br \\ Dayane Neves Sousa \\ Universidade Federal de Viçosa \\ sousadayane@ymail.com
}

\section{Resumo}

Este trabalho procura mostrar a experiência do Projeto de Assessoramento as Comunidades Atingidas por Barragens e Mineração (PACAB) junto às comunidades que poderão ser atingidas pelo mineroduto da empresa Ferrous na microrregião de Viçosa, Minas Gerais. Os integrantes do PACAB entendem que a assessoria é compreendida como uma ação de mediação e aprendizado coletivo. Como ações foram realizadas reuniões e mobilizações junto às comunidades atingidas pelo empreendimento. Dentre os resultados, verificou-se que o trabalho de assessoria realizado pelo PACAB contribuiu para a criação da Campanha pelas Águas e Contra o Mineroduto da Ferrous e ofereceu suporte técnico as famílias atingidas por tal empreendimento.

Palavras-chave: assessoria; mineroduto da Ferrous; microrregião de Viçosa-MG.

\section{AN EXPERIENCE OF ADVICE IN COMMUNITIES AFFECTED OF THE PIPELINE FERROUS IN ZONA DA MATA MINEIRA}

\begin{abstract}
This work aims to show the experience of the Project Consulting Communities Affected by Dams and Mining (PACAB) with the communities affected by the pipeline Ferrous in micro region Viçosa, Minas Gerais. Members of PACAB understand that the advice is understood as an act of mediation and collective learning. How actions and mobilizations meetings with the communities affected by the project were made. Among the results, it was found that the advisory work carried out by PACAB contributed to the creation of the Campaign Against Water and Pipeline Ferrous in Viçosa and offered technical support families affected by this undertaking.

Key-words: advice; pipeline Ferrous; micro region Viçosa-MG.

\section{UNA EXPERIENCIA DE ASESORÍA JUNTO A LAS COMUNIDADES AFECTADAS POR EL MINERODUCTO DE LA FERROUS EN LA MATA MINEIRA}

\section{Resumen}

Este trabajo pretende mostrar la experiencia del Proyecto de Asesoramiento a las Comunidades Afectadas por Represas y Mineración (PACAB) junto a las comunidades que podrán ser afectadas por el mineroducto de la empresa Ferrous en la microrregión de Viçosa, Minas Gerais. Los integrantes del PACAB entienden que la asesoría es comprendida como una acción de mediación y aprendizaje colectivo. Como acciones fueron realizadas reuniones y movilizaciones junto a las comunidades afectadas por el emprendimiento. Dentro de los resultados se verifico que el trabajo de asesoría realizado por el PACAB contribuyo para la creación de la Campaña por las Aguas y Contra el Mineroducto de la Ferrous y ofreció soporte técnico a las familias afectadas por tal emprendimiento.

Palabras clave: Asesoría; mineroducto de la Ferrous; microrregión de Viçosa-MG 


\section{INTRODUÇÃO}

Este trabalho pretende trazer a luz do debate uma experiência sobre a assessoria que o grupo de extensão universitária Projeto de Assessoria as Comunidades Atingidas por BarragensPACAB, locado no Departamento de Economia Rural da Universidade Federal de Viçosa - UFV, vem fazendo junto com as comunidades que poderão ser atingidas pelo mineroduto da empresa Ferrous na microrregião de Viçosa, Minas Gerais.

O PACAB é um grupo composto por professores e alunos da UFV e que vem prestando assessoria às comunidades atingidas por barragens na região da Zona da Mata Mineira a mais de 18 anos. A partir do ano de 2011, o PACAB passou a assessorar também as comunidades atingidas por empreendimentos ligados a mineração que vem crescendo nesta região, sobretudo, junto às famílias que possivelmente serão atingidas pelo mineroduto da Ferrous. Além desse tipo de assessoria, o grupo vem discutindo a problemática relativa aos usos dos recursos naturais, principalmente, água e minério.

Nesse sentido, um dos focos de atuação da assessoria se refere ao processo de capacitação e mediação dos atingidos por tais empreendimentos. É importante destacar que entre os anos de 2013-2014 e 2014-2015 o PACAB foi contemplado com recursos financeiros do Programa de Extensão Universitária-PROEXT para atuar no assessoramento às comunidades que se encontram atingido por empreendimentos de infraestrutura e de mineração.

A experiência a ser apresentada neste trabalho iniciou-se no ano de 2011 quando os integrantes do PACAB e entidades estudantis da UFV realizaram as primeiras mobilizações e discussões acerca dos impactos e dos conflitos ambientais que estavam iniciando na microrregião de Viçosa, frente a possível instalação do mineroduto da Ferrous. Do ponto de vista da assessoria o grupo se orientou na articulação e mobilização das comunidades atingidas, bem como na atuação em parceria com os movimentos sociais que atuam nesse território.

Do ponto de vista acadêmico e de interação universidade-sociedade, essa experiência tem todos os ingredientes para isso. Nesse sentido, o trabalho vem se pautando no esforço de criar uma interface com duas disciplinas, que são ministradas pelo primeiro autor desse artigo, sendo uma de graduação denominada Extensão Rural e a outra de pós-graduação do programa em Extensão Rural designada Conflitos Ambientais. Esta disciplina da pós-graduação procura problematizar a opção desenvolvimentista, os impactos junto ao meio ambiente, racismo ambiental, justiça ambiental e conflitos ambientais. Portanto, a experiência do projeto e o convívio junto às comunidades que poderão ser atingidas tem sido de grande valia para reflexões entre universidade e comunidade. 


\section{MATERIAIS E MÉTODOS}

O empreendimento escolhido pelo PACAB para a realização da assessoria junto às comunidades atingidas foi o mineroduto da empresa Ferrous. Este empreendimento ligará o complexo da Mina da Viga, no município de Congonhas-MG, ao porto da Ferrous, em Presidente Kennedy-ES. O mineroduto passará por 22 municípios, sendo 17 em Minas Gerais, 03 no Rio de Janeiro e 02 no Espírito Santo. Nesse momento, é importante mencionar que o mineroduto encontra-se na fase de licenciamento ambiental, preiteando a Licença de Instalação junto ao Instituto Brasileiro do Meio Ambiente e dos Recursos Naturais-IBAMA. Na Ilustração 01 é possível observar o trajeto do Mineroduto.

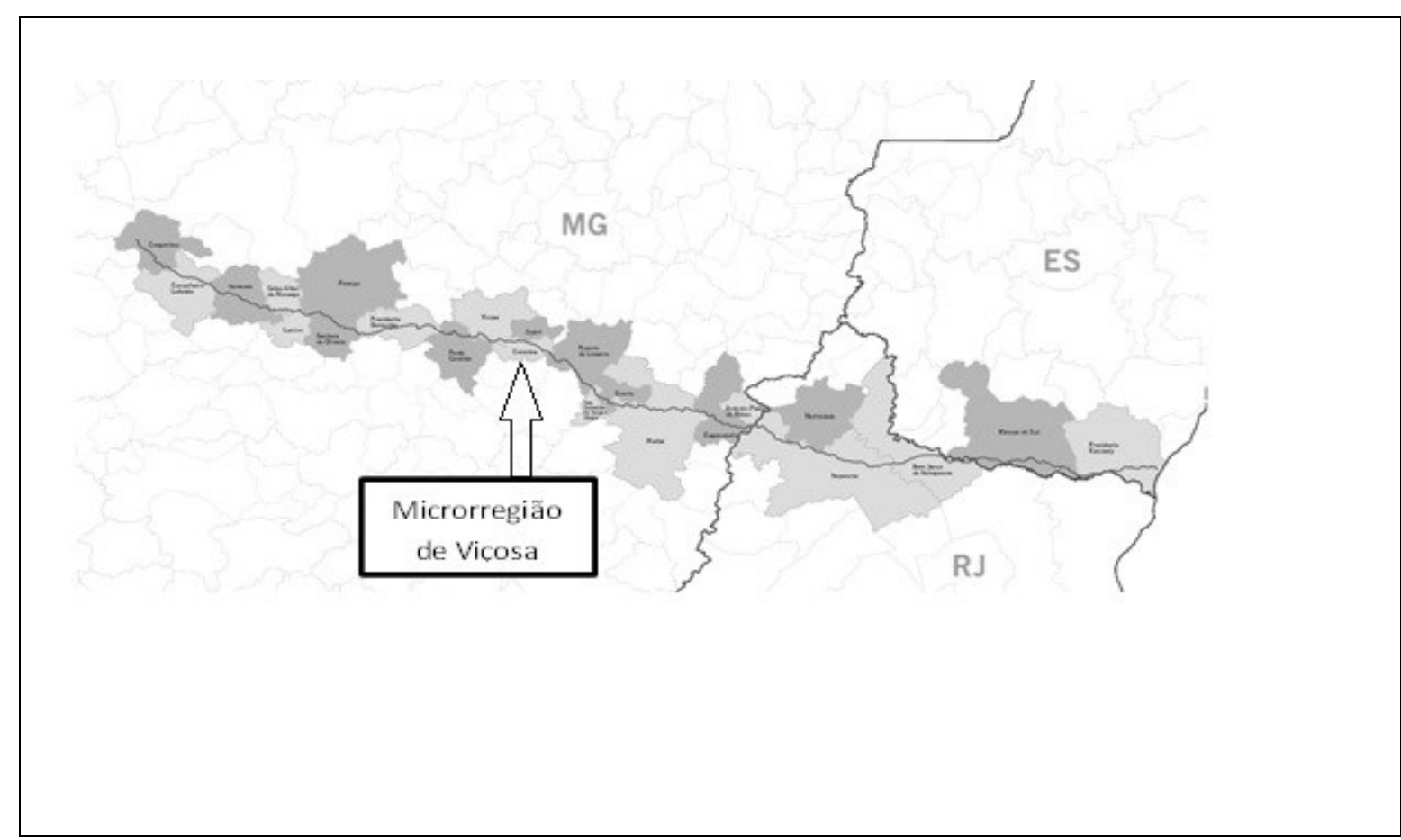

Ilustração 01 - Trajeto do mineroduto da Ferrous saindo do município de Congonhas - MG, até o porto da "Ferrous Ressources”, em Presidente Kennedy - ES. Com destaque para Microrregião de Viçosa-MG.

Fonte: Adaptado de Sousa et. al. (2013).

O trabalho de assessoria foi estabelecido como uma ação de mediação e aprendizado coletivo junto às famílias atingidas e suas entidades de representação. Assim, esse trabalho se pautou nos ensinamentos de Paulo Freire (1992) que preconiza a importância de se criar uma relação dialógica por meio de uma educação libertadora que possibilita a inserção de práticas autônomas como instrumentos democratizantes da relação nos trabalhos de mediação. Nessa perspectiva, este autor, acredita que a educação libertadora tem como objetivo principal ser um instrumento no qual os atores sociais envolvidos nesse processo construíssem juntos um novo 
saber que não mais subjugasse os interesses dos grupos assistidos, mas que, pelo contrário, os libertasse.

Nesse sentido, a escolha do instrumento dialógico foi fundamental para que se estabelecesse uma relação de confiança entre as comunidades de Viçosa assessoradas e o PACAB. Como forma de concretizar o trabalho de assessoria foi necessária que o grupo criasse espaços propícios à realização de dinâmicas interativas e discursivas por meio de rodadas de reuniões na UFV e em diversos pontos da cidade de Viçosa. Essa ação de diálogo e mobilização colheu frutos positivos, ou seja, a partir destas ações foi constituída no município de Viçosa, no ano de 2012, a Campanha pelas Águas e Contra o Mineroduto da Ferrous envolvendo não só os atingidos pelo empreendimento, mas também os moradores da cidade de Viçosa, da microrregião de Viçosa e os universitários. A campanha possui um blog no qual são postadas todas as informações sobre o mineroduto da Ferrous.

É importante destacar que esse trabalho de assessoria contou com a parceria de outros grupos, como: Movimento dos Atingidos Por Barragens-MAB, os movimentos estudantis ligados a cursos de graduação da UFV como Entidade Nacional de Estudantes de Biologia-ENEBio, Associação Brasileira de Estudantes de Engenharia Florestal-ABEF, Igreja Católica-Paróquia de Nossa Senhora de Fátima-Viçosa, Levante Popular da Juventude, Associação dos Geógrafos do Brasil-AGB seção Viçosa, além da ONG Núcleo de Assessoria a Comunidades Atingidas por Barragens-NACAB.

\section{RESULTADOS E ANÁLISES}

A movimentação sobre a instalação de um empreendimento da magnitude do Mineroduto da Ferrous na região é datada do ano de 2010 quando foram realizados os Estudos de Impacto Ambiental - EIA e Relatório de Impacto Ambiental - RIMA com o objetivo de conseguir a licença prévia do empreendimento. Essa licença foi concedida pelo IBAMA, órgão responsável pelo licenciamento na esfera federal. O processo de envolvimento do grupo com os atingidos tem como marco, o ano de 2011, quando o PACAB abordou por meio de reuniões os possíveis impactos e os problemas relativos ao grande número de ações jurídicas acerca das indenizações proposta pelo empreendedor na Câmara de Vereadores de Viçosa.

Esse evento acendeu a luz para que as comunidades da região se mobilizassem entorno de pautas contrárias a instalação do empreendimento. Dentre as três grandes reuniões citam-se: 
a) Audiência Pública da Comissão de Minas Energia da Assembleia Legislativa de Minas Gerais, realizada em dezembro de 2011. Esta audiência teve o objetivo de realizar o debate sobre os impactos da construção do mineroduto da Ferrous entre os municípios do trajeto do empreendimento.

b) Passeata contra o mineroduto da Ferrous e em defesa das águas, realizada em maio de 2012. Esta passeata teve o propósito de manifestar a insatisfação da implantação do projeto do mineroduto da Ferrous, no município de Viçosa, para a comunidade Viçosense, o Estado e a empresa Ferrous.

c) Audiência Pública promovida pelo Ministério Público do Estado de Minas Gerais (MPMG), realizada em julho de 2012. Esta audiência pública foi realizada com a intenção de que a comunidade atingida direta e indiretamente pelo o mineroduto explanasse sobre os impactos ambientais e sociais que estão enfrentando frente à implementação do mineroduto da Ferrous, para o Ministério Público do estado de Minas Gerais.

É importante destacar que, no início do ano de 2012, alguns bairros de Viçosa passaram por racionamento de água, em razão de problemas técnicos do órgão responsável por distribuir água em Viçosa - Serviço Autônomo de Água e Esgoto de Viçosa-SAAE, mas esse fato serviu de exemplo para um possível colapso permanente do estoque de água caso o mineroduto seja construído. Pois, o traçado do mineroduto está projetado para passar próximo às nascentes do Ribeirão São Bartolomeu, uma das principais fontes de água que abastece o município e o temor dos viçosenses é que o empreendimento possa comprometer esse recurso no futuro.

Além disso, as águas do Ribeirão São Bartolomeu abastecem 100\% a UFV e um impacto em suas nascentes poderia comprometer o abastecimento de água da instituição e até mesmo suspender as aulas. Essa realidade tem contribuído para discussões na própria universidade, configurando com um debate organizado pelo PACAB e pela Campanha Pelas Águas Contra o Mineroduto da Ferrous. Esse evento foi realizado em maio de 2014 e teve por objetivo trazer reflexões sobre os impactos desta obra não só nas comunidades atingidas como, também, no campus da UFV. Na Ilustração 02 é possível observar o cartaz de divulgação do evento. A própria manchete do cartaz “Mineroduto em Viçosa! Impactos na UFV?” Traz uma reflexão para os universitários e os seus dirigentes sobre os impactos que o mineroduto traria para a UFV. 


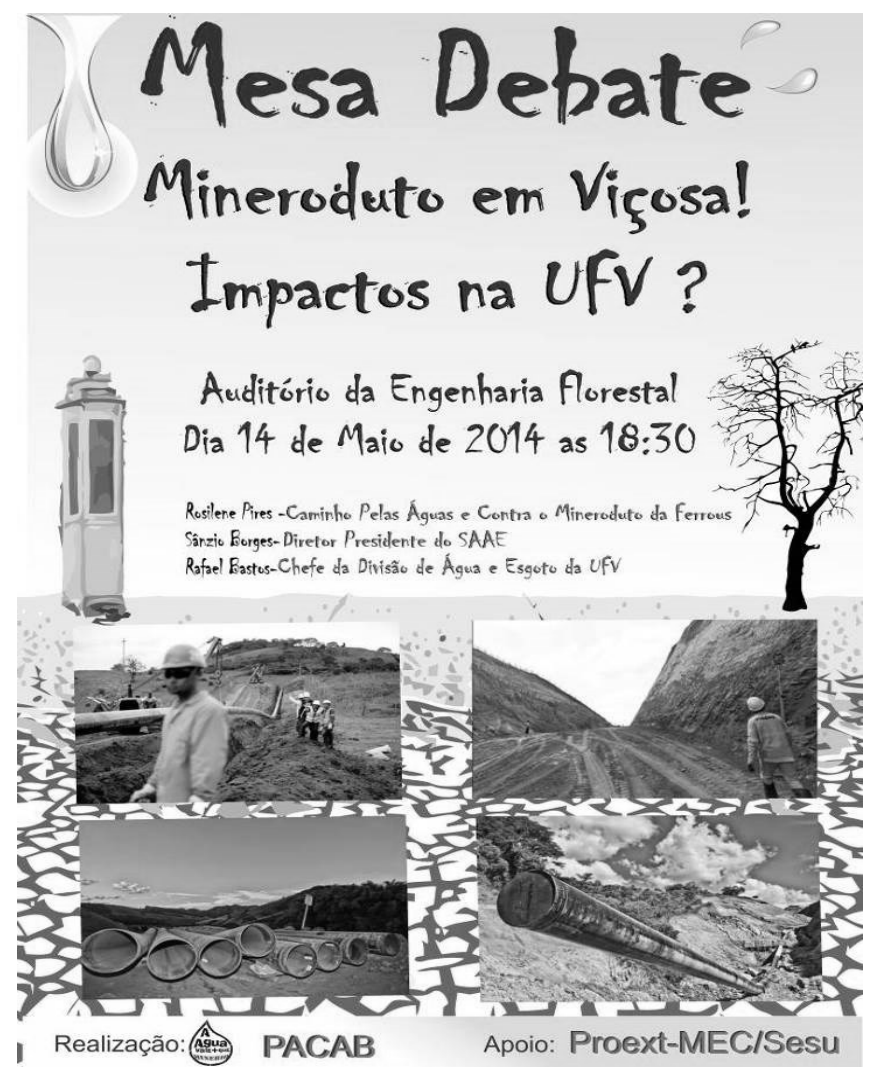

Ilustração 02 - Cartaz de divulgação do debate sobre a passagem do mineroduto em Viçosa-UFV Fonte: Acervo do PACAB (2014)

No debate as posições das falas dos palestrantes e dos participantes foram no caminho de apontar que a presença do mineroduto no município trará consequências negativas, tanto do ponto de vista socioeconômico para as famílias atingidas, como para meio ambiente local, sobretudo, no que tange aos aspectos hídricos da cidade de Viçosa.

Além disso, as falas dos presentes foram no intuito de provocar uma posição dos dirigentes da UFV sobre essa realidade que pode inclusive comprometer o abastecimento de água da universidade e, consequentemente, o funcionamento do campus. Portanto, o trabalho de assessoria promovida pelo $\mathrm{PACAB}$ juntamente com outros movimentos sociais trouxe para o campus universitário reflexões que contribuíram para que a comunidade universitária se atentasse para esse eminente problema que ronda não só o campus mais a própria cidade de Viçosa.

Ao longo desse trabalho de assessoria algumas questões foram trazidas a luz do debate, entre elas: é possível relacionar o problema do modelo de desenvolvimento desigual no qual a transferência dos bens naturais como água, minério e biodiversidade ocorre de forma injusta e que a maioria da população não é beneficiaria desse modelo de exploração.

Outra reflexão importante que o projeto de assessoria contribuiu foi trazer à baila a questão da violação dos direitos humanos que acomete com essa população afetada pelo 
empreendimento. No caso do mineroduto da Ferrous foi possível levantar relatos de famílias que estavam coagidas a venderem suas propriedades para o empreendedor, bem como a negociação sendo realizada de forma desigual entre gênero e entre condições socioeconômicas. Nesse sentido a fala de uma atingida representante da Campanha, descreve bem essa situação. "Lá na minha comunidade em Paula Candido [município vizinho a Viçosa], a pessoa da empresa chegon a negociar o mesmo tamanho de terra por preços diferentes [...] no caso da família simples eles pagaram um valor bem menor do que o outro proprietário que era professor da UFV" (ATINGIDA PELO MINERODUTO DA FERROUS, 2014). Esta fala representa uma das formas desiguais que o empreendedor vem tratando a questão dos atingidos por tal empreendimento.

Portanto, é possível refletir que essa articulação promovida pela assessoria converge com a ideia de Justiça Ambiental que corresponde a uma nova perspectiva integrando as lutas ambientais e sociais contra um modo de produção excludente e degradadora. Que não levaria em conta que os grupos mais pobres e menos desprovidos de poder que pagam a conta pela exploração ou na disposição dos resíduos no meio ambiente, ou seja, os riscos ambientais recaem sobre os mais pobres (ACSELRAD et. al. 2009).

Seguindo essa linha de raciocínio, Martinez (2011) traz a discussão dos problemas sociais no campo do conflito com a discussão do Ecologismo dos Pobres. Esta teoria traz os dilemas que envolvem o desenvolvimento nos países em desenvolvimento e os desequilíbrios de poder a ele associados, os quais são tensionados de ambas as partes. De um lado pelo discurso associado à racionalidade desenvolvimentista orientada pelo crescimento econômico e, de outro, as articulações de movimentos sociais e atores políticos reivindicantes dos direitos dos atingidos ou simplesmente marginalizados pelo processo, muito embora não deixem de sofrer com as suas consequências nefastas.

\section{CONSIDERAÇÕES FINAIS}

Ao longo dessa experiência de assessoria as comunidades atingidas por empreendimentos ligados à mineração, o que fica para os integrantes do PACAB é o papel importante da extensão universitária no sentido de contribuir não só no acompanhamento das comunidades atingidas, mas como fomentador de reflexões sobre o uso e a forma como os recursos ambientais têm sido utilizados por nossa sociedade.

No caso do PACAB os ganhos que ficam para o grupo é a certeza que o papel da universidade vai além de produzir conhecimento. É preciso que esse conhecimento esteja 
disponível para a sociedade extramuros da universidade, sobretudo àquelas populações carentes de formação técnica e reféns de um processo desenvolvimentista. Assim, o papel de assessoria do grupo tem tentado aproximar esse conhecimento científico com as reais demandas desses grupos atingidos por empreendimentos de infraestrutura, principalmente, em relação ao mineroduto da Ferrous.

Por outro lado, o trabalho de extensão universitária permitiu que a problemática envolvendo as questões ambientais e sociais provocadas por esse empreendimento assistido pela assessoria fossem compartilhadas junto aos alunos que participam do projeto sejam na forma de visitas ou até mesmo na contribuição técnica realizadas em comunidades que vivenciam os conflitos.

Além disso, essa experiência de assessoria é compartilhada junto aos alunos das disciplinas de graduação (ERU-451 Extensão Rural) para alunos dos cursos de Ciências Agrárias e de pós-graduação (ERU-731 Conflitos Ambientais) no programa de Pós Graduação em Extensão Rural da Universidade Federal de Viçosa. O que permite trazer para os contextos das aulas realidades vividas e experimentadas na extensão universitária.

\section{AGRADECIMENTOS}

Os autores agradecem os recursos disponibilizados pelo Programa de Extensão Universitária - Proext que financiou, nos anos de 2014 e 2015, o Projeto Assessoria às Comunidades Atingidas Pelos Impactos Sociais e Ambientais causados por projetos de barragens e mineração na Zona da Mata/MG.

\section{REFERÊNCIAS}

ACSELRAD, Henri; MELLO, Cecília Campello do A; BEZERRA, Gustavo das Neves de. O que é justiça ambiental. Rio de Janeiro: Garamond, 2009.

BLOG CAMPANHA PELAS ÁGUAS. Campanha pelas águas e contra o Mineroduto da Ferrous. Disponível em: <http://campanhapelasaguas.blogspot.com.br/>. Acesso em: 31 de Nov. 2013.

FREIRE, Paulo. Extensão ou comunicação? Rio de Janeiro: Ed. Paz e Terra, 1992.

MARTÍNEZ Alier, Joan. Origens e campo de atuação da Ecologia Política. In: O Ecologismo dos pobres. São Paulo: Contexto. 2011. 
PASCHECO, Aguinaldo. Assembleia Popular para discutir o Mineroduto da Ferroous. Disponível em: <http://vicosacidadeaberta.blogspot.com.br/2012/04/assembleia-popular-paradiscutir-o.html>. Acesso em 10 de Set. 2013.

SOUSA, Dayane Rouse Neves; OLIVEIRA, Marcelo Leles Romarco; FONSECA Bruno Costa. Conflitos na implantação do Mineroduto da Ferrous: a percepção dos atores sociais sob suas causas e desdobramentos. RDG-Revista do Departamento de Geografia da USP. V. 25, p.140-163, 2013. 